\title{
Conexões e interações do processo de criação no ensino remoto do design: fluxo e trânsito entre documentos de processo na disciplina Projeto Sentir
}

Marcelo J. O. de Farias ${ }^{1}$

\author{
Caracterização geral do design
}

DESIGN É UMA ATIVIDADE QUE DÁ FORMA E PLASMA À CULTURA MATERIAL E IMATERIAL PARA ATENDER DETERMINADAS necessidades práticas ou produzir efeitos de sentido, dirigidas, prioritariamente, ao ser humano, ou seja, trata-se de uma ação criativa, orientada pelo projeto, que envolve processos de observação, imaginação, configuração e representação, com o propósito de combinar, organizar e compor elementos técnicos e estéticos numa linguagem visual bidimensional e/ou tridimensional, no contexto analógico e/ou digital. Nessa práxis, o modo de construção e desenvolvimento do pensamento do designer ocorre no amálgama entre o processo de criação e o desenvolvimento do projeto ou projetação.

Assim, o percurso do projeto em design é entendido como método e plano lógico que descreve, traça e rege o espaço da criação, constituído de uma estrutura e eixo de fases e atividades que se caracterizam num certo modo de pensar, próprio do design. Assim, o projeto é fator determinante do processo de criação. Sabemos, contudo, que tanto a criação quanto o projeto são processos utilizados em distintas atividades. No entanto, “[...] o design se diferencia de outros processos de configuração justamente pela lógica que pretende, ou seja, o design é essencialmente uma práxis que procura seguir princípios de diversas ciências ou na determinação da figura dos objetos".

\section{Contexto do ensino remoto do design}

O ensino remoto ${ }^{3}$ trouxe à tona uma série de discussões, desafios e possibilidades que afetaram instituições, professores e alunos. Certamente essa modalidade não será uma experiência momentânea ou passageira, mas um marco para reflexões e oportunidades que demandam mudanças significativas no modo como ensinamos e aprendemos. Nesse momento de redefinição os cursos de nível superior buscam por soluções que garantam a continuidade e o desenvolvimento das atividades acadêmicas, cada instituição segundo seus recursos disponíveis, gerando manobras coletivas em direções variadas, que

\footnotetext{
${ }^{1}$ Doutor e mestre em comunicação e semiótica pela Pontifícia Universidade Católica de São Paulo - PUC/SP; Pós-Graduado em Design Management pela Università degli Studi di Roma "La Sapienza", Itália; Pós-Graduado em Design pelo Centro de Diseño Industrial - CDI/FADU, Uruguai; Graduado em Desenho Industrial pela Universidade Federal da Paraíba - UFPB. Professor dos cursos de graduação em Design e de Moda da Faculdade Armando Alvares Penteado - FAAP/São Paulo, e professor do curso Bacharelado em Design do Centro Universitário Senac- Santo Amaro, São Paulo.

${ }^{2}$ Bomfim, Gustavo A.; Portinari, Denise B. Epistemologia do design. In: COUTO, Rita Maria de S., FARBIARZ, Jackeline L e NOVAES, Luiza (Ogs.). Gustavo Amarante Bomfim uma coletânea. Rio de Janeiro: Rio Book's, 2014, p. 114.

${ }^{3}$ Trata-se de aulas virtuais ministradas em tempo real pelo professor responsável da disciplina, onde basicamente todo conteúdo é produzido e disponibilizado online. O Ministério da Educação (MEC) determinou e autorizou em 2020 a utilização das aulas remotas em escolas e universidades enquanto durar a pandemia de COVID 19 no Brasil. Disponível em: <https://www.in.gov.br/en/web/dou/-/portaria-n-544-de-16-de-junho-de-2020-261924872>. Acesso em: 12 de abr. 2021.
} Conexões e interações do processo de criação no ensino remoto do design: fluxo e trânsito entre documentos de processo na disciplina Projeto Sentir 
resultam no uso de novas plataformas, procedimentos e ferramentas no ambiente acadêmico. Diante de tais circunstâncias e condições, certamente, é preciso abrir mão do estabelecido e firmado, sem perder de vista as experiências adquiridas.

Nesse sentido, o ensino remoto não se trata de um rebatimento ou espelhamento das aulas presenciais, nem tão pouco uma extensão ou variação da modalidade do ensino a distância ${ }^{4}(\mathrm{EaD})$, mas de uma categoria em construção. Assim, as limitações, restrições, barreiras e disponibilidades de recursos materiais e imateriais são variáveis incontroláveis que moldam o desenvolvimento das aulas. O espaço físico, por exemplo, se converte, simultaneamente, em sala de aula, laboratório, oficina, ateliê e moradia. As interações e interlocuções são mediadas pelos ambientes virtuais de aprendizagem ${ }^{5}$ (AVA), disponibilizados pelas instituições de ensino. Dentre esses podemos destacar algumas, Google Suite, Canvas, Blackboard, G. Classroom, Moodle, utilizados de modo combinado aos objetos virtuais de aprendizagem ${ }^{6}$ (OVA), seja de geração de conteúdo, de comunicação e criação de comunidade, de organização, aprendizagem e avaliação, dentre outros, disponibilizados em diversas modalidades de acesso. No entanto, é preciso considerar que essas possibilidades digitais são percebidas simultaneamente de modos distintos por professores e alunos no processo de ensino e aprendizagem remoto, pois as condições e configurações físicas, materiais e tecnológicas geram estímulos únicos entre os participantes.

As reflexões apresentadas e discutidas partiram das experiências realizadas no contexto do ensino remoto da disciplina Projeto Sentir, que integra o primeiro período do programa do curso de design no Centro Universitário Senac - Santo Amaro, desenvolvidas no ano letivo de 2020. Em síntese o Projeto Sentir propicia reflexão e experimentação da percepção sensorial, da memória, das sensações, dos sentimentos e das emoções por meio do desenvolvimento de projeto. Por meio dessa experiência de ensino e aprendizagem foram observadas e analisadas as ações dos alunos em suas estratégias processuais criativas em rede a partir das interações com os documentos de processo de criação.

Diante desse contexto em processo de descoberta, as estratégias processuais criativas nas aulas remotas buscam respostas e soluções num movimento colateral ao método do projeto em design, que comumente segue uma sequência lógica e progressiva, abrindo, assim, espaço para as eventualidades, intervenções do inesperado e do imprevisto. Essa condição de ensino e aprendizagem, contudo, oferece oportunidades para discutir aspectos relacionados aos documentos de criação no trânsito entre analógico e digital. Ampliando a compreensão das manobras e articulações do pensamento no processo de ensino do design.

Utilizamos o termo documentos de processo, proposto pela teoria da crítica de processo de criação ${ }^{7}$, que investiga os processos de criação e sua morfologia no âmbito do design e de áreas afins, abrangendo uma diversidade de materiais, linguagens, suportes e tecnologias que compõem os arquivos. Assim, "pode se dizer que esses documentos, independentemente de sua materialidade, contêm sempre a ideia de registro" ${ }^{8}$ A ideia de registro tem finalidade e sentido que pode variar, de acordo com o propósito do criador. Assim, os documentos cumprem distintas funções: preservar e

\footnotetext{
${ }^{4}$ A Educação a Distância é a modalidade educacional na qual a mediação didático-pedagógica nos processos de ensino e aprendizagem ocorre com a utilização de meios e tecnologias de informaçãoo e comunicação, com estudantes e professores desenvolvendo atividades educativas em lugares ou tempos diversos. Esta definição está presente no Decreto 5.622, de 19.12.2005 (que revoga o Decreto 2.494/98), que regulamenta o Art. 80 da Lei 9.394/96 (LDB). Disponível em: <http://portal.mec.gov.br/instituicoes-credenciadas/educacao-superior-a-distancia >. Acesso em: 12 de abr. 2021.

${ }^{5}$ São plataformas digitais que auxiliam na montagem de cursos acadêmicos pela Internet. Elaborado para ajudar os professores e tutores no gerenciamento de conteúdos para seus alunos e na administração do curso, permitindo acompanhar constantemente o progresso dos estudantes.

${ }^{6}$ São recursos digitais que podem ser utilizados por professores e alunos como suporte ao ensino. Para isso, essas ferramentas precisam ser interativas e contar com um objetivo educacional bem definido, possibilitando ao aluno refletir e traçar inferências ao longo de seu uso.

${ }^{7}$ SALLES, Cecilia Almeida. Gesto Inacabado: processo de criação artística. $5^{\mathrm{a}}$. ed., São Paulo: Intermeios, 2011, p. 21).

${ }^{8}$ Ibidem, p. 26.
}

Conexões e interações do processo de criação no ensino remoto do design: fluxo e trânsito entre documentos de processo na disciplina Projeto Sentir 
memorizar o processo; organizar dados e informações; experimentar, avaliar e validar as escolhas e decisões; estabelecer diálogo interpessoal com o conteúdo produzido e mediar a comunicação nos processos de interlocução. Sabemos, contudo, que essas funções têm objetivo analítico, pois os documentos se sobrepõem e se entrelaçam na práxis do design.

O projeto de design se configura como o processo de elaboração do conjunto de documentos necessários à execução de qualquer objeto, seja este de qualquer dimensão ou característica, tendo sido desenvolvido a partir da construção do problema em multiplicadas derivações, por exemplo: quanto a seu significado, quanto a aspectos de produção, quanto a múltiplos aspectos de uso e funcionamento, quanto ao impacto no meio ambiente, quanto às ferramentas projetivas, entre outras tantas, inclusive os aspectos subjetivos de quem projeto. ${ }^{9}$

Em tais circunstâncias de ensino, destacamos na disciplina projeto sentir a função comunicacional dos documentos de processo de criação na relação do aluno com sua produção, assim como, na relação interpessoal com o professor e com os outros alunos, consequentemente, detonando reflexões sobre processos de aquisição de conhecimentos e o desenvolvimento da consciência do ato de projetar. A análise dos documentos de processo evidencia a rede de associações de ideias, pensamentos, conceitos, teorias etc., indicando como se desencadeiam e porque algumas diretrizes de criação são escolhidas em detrimento a outras. Acrescentar seu próprio elo à corrente é um modo do aluno encontrar sua própria voz.

O fluxo entre os documentos analógicos e digitais no Projeto Sentir se deu no contexto do ambiente virtual de aprendizagem, Blackboard, que disponibiliza recursos de interação, compartilhamento, discussão, dentre outros. Nesse ambiente evidenciamos o compartilhamento do quadro branco, como recurso para apoiar discussões e proposições de ideias através de esboços, desenhos, anotações, comentários etc., permitindo que professor e alunos interajam simultaneamente durante as atividades, adicionando, modificando, apagando ou complementando elementos ao conteúdo do quadro. Essa operação caracteriza a rede de associações de ideias, pensamentos, conceitos, teorias etc., revelando como os estratos individuais se fundem formando uma estrutura homogênea que parte do coletivo.

No contexto do ensino remoto do design, os documentos de criação tornam-se componentes imprescindíveis no processo de aprendizagem do ato de projetar. As novas tecnologias, suportes, linguagens e meios contribuem para o aumento da diversidade e expansão dos arquivos da criação. Nesse sentido, são instrumentos que agem como detonadores da consciência do aluno em relação ao seu próprio processo. Sendo o aluno capaz de contribuir com o (re)pensar a criação em design nesse novo contexto.

As experiências desenvolvidas durante as aulas remotas do Projeto Sentir indicam e revelam que o compartilhamento e troca de ideias, opiniões e experiências é intensificado entre os participantes quando não existe barreira, distinção ou determinação em relação ao tipo de suporte, meio ou linguagem a ser utilizada na comunicação. Assim, o aluno pode fazer um esboço, desenho ou colagem no seu sketchbook, bem como, construir um modelo tridimensional, utilizando papel, tesoura, fita adesiva e direcionar para a câmera do seu computador ou celular, bem como, compartilhar o quadro branco do Blackboard e desenhar um diagrama, esquema para expor seu pensamento sobre a questão discutida no projeto (Figura 1). Nesse sentido, identificamos que o fluxo livre e espontâneo entre documentos analógicos e digitais, foi intensificado nessa condição de ensino e aprendizagem.

\footnotetext{
${ }^{9}$ Coelho, Luiz Antônio L. (Org.). Conceitos-chave em design. Rio de Janeiro: Ed. PUC-Rio. Novas Ideias, 2011 , p. 269.
} 


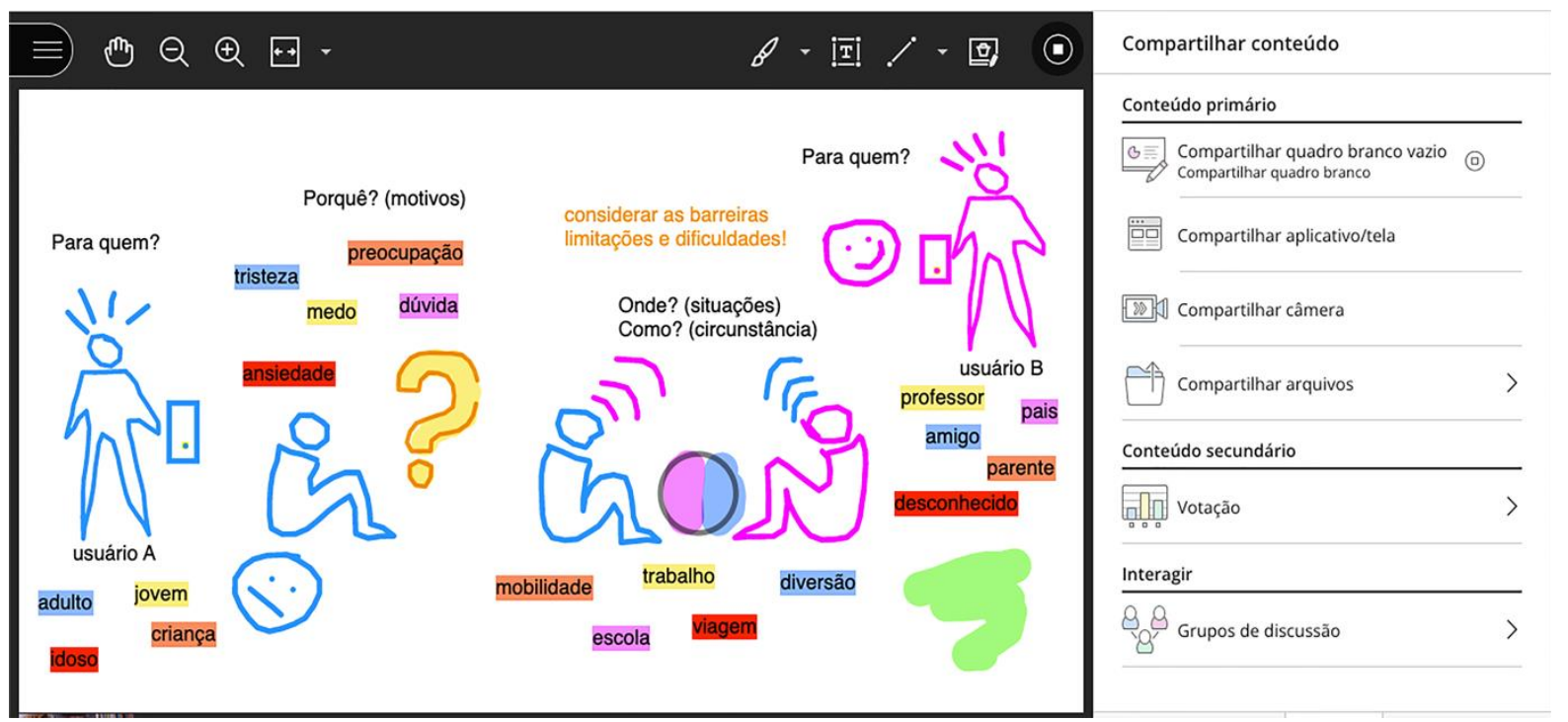

Fig. 1. Diagrama de discussão sobre projeto em design, desenvolvido pelo próprio autor no quadro branco do ambiente virtual de aprendizagem, Blackboard, 2020. Screenshot realizado pelo autor.

\section{Processo de criação e projeto em rede}

É preciso sublinhar que o processo de criação no design não é um período ou fase do método de projeto, definido como estágio circunscrito de produção de novas ideias, mas um processo contínuo e entrelaçado ao percurso do projeto, dado pela combinação, união e ordenação de elementos materiais e imateriais que, a princípio, encontravam-se separados, e que, aos poucos, vão formando partes constituintes de um todo.

O projeto de design, nesse sentido, define as coordenadas do trajeto do pensamento criador, delineando e programando a intenção e o propósito de fazer ou realizar algo. Assim descrito, o projeto é compreendido também como vetor, força ou tendência imprimindo certo modo de pensar, guiando o pensamento, como "qualquer coisa que esteja presente à mente, seja ela de uma natureza similar às frases verbais, a imagens, a diagramas de relações de quaisquer espécies, a reações e sentimentos $[. . .]^{110}$, a fim de estabelecer associações e combinações significativas, que remetam ao que se pretenda alcançar.

A ideia de criação associada ao pensamento livre, a esmo, sem fundamento, seguindo na direção do vento é sedutora, mas não representa manobras, articulações, tensões e conflitos que fazem parte do processo de criação. Verificamos, contudo, que o componente abstrato e as operações intelectuais que compõem a criação abrem espaço às representações, visões e imagens variadas. Portanto, as soluções do projeto de design "[...] são resultado de um processo criativo, cuja natureza é apenas parcialmente compreendida. O que é que dá início ao processo, e o que é que dispara um lance decisivo no desenvolvimento?". ${ }^{11}$

No Projeto Sentir as discussões iniciais são disparadas a partir do desenvolvimento de diagramas, esquemas e mapas visuais. Assim, o significado de sentir é definido coletivamente e simultaneamente através da associação e combinação de palavraschave, compondo um mapa conceitual a partir do entendimento e experiência de cada aluno. Para executar esse documento foi utilizado o objeto virtual de aprendizagem (OVA) Miro, que disponibiliza recursos gráficos variados. Partindo desse mapa conceitual preliminar os alunos interpretam o sentir através de uma composição gráfica individual utilizando a técnica da colagem com imagens impressas, disponíveis em revistas, jornais etc., compondo uma narrativa visual compartilhada com os

${ }^{10}$ SANTAELLA, Lúcia. Matrizes da linguagem e pensamento: sonoro, visual e verbal: aplicação na hipermídia. $3^{\text {a }}$ ed., São Paulo: Iluminuras: FAPESP, 2005, p. 55.

${ }^{11}$ BERNSEN, Jeans. Design: defina primeiro o problema. SENAI/LBDI, 1995. 
demais alunos durante a aula (Figura 2). Naturalmente, as restrições e limitações, bem como, o fluxo e trânsito entre o analógico e digital fazem parte do processo de aprendizagem, desenvolvendo habilidades múltiplas, dissolvendo fronteiras e ampliando as conexões.

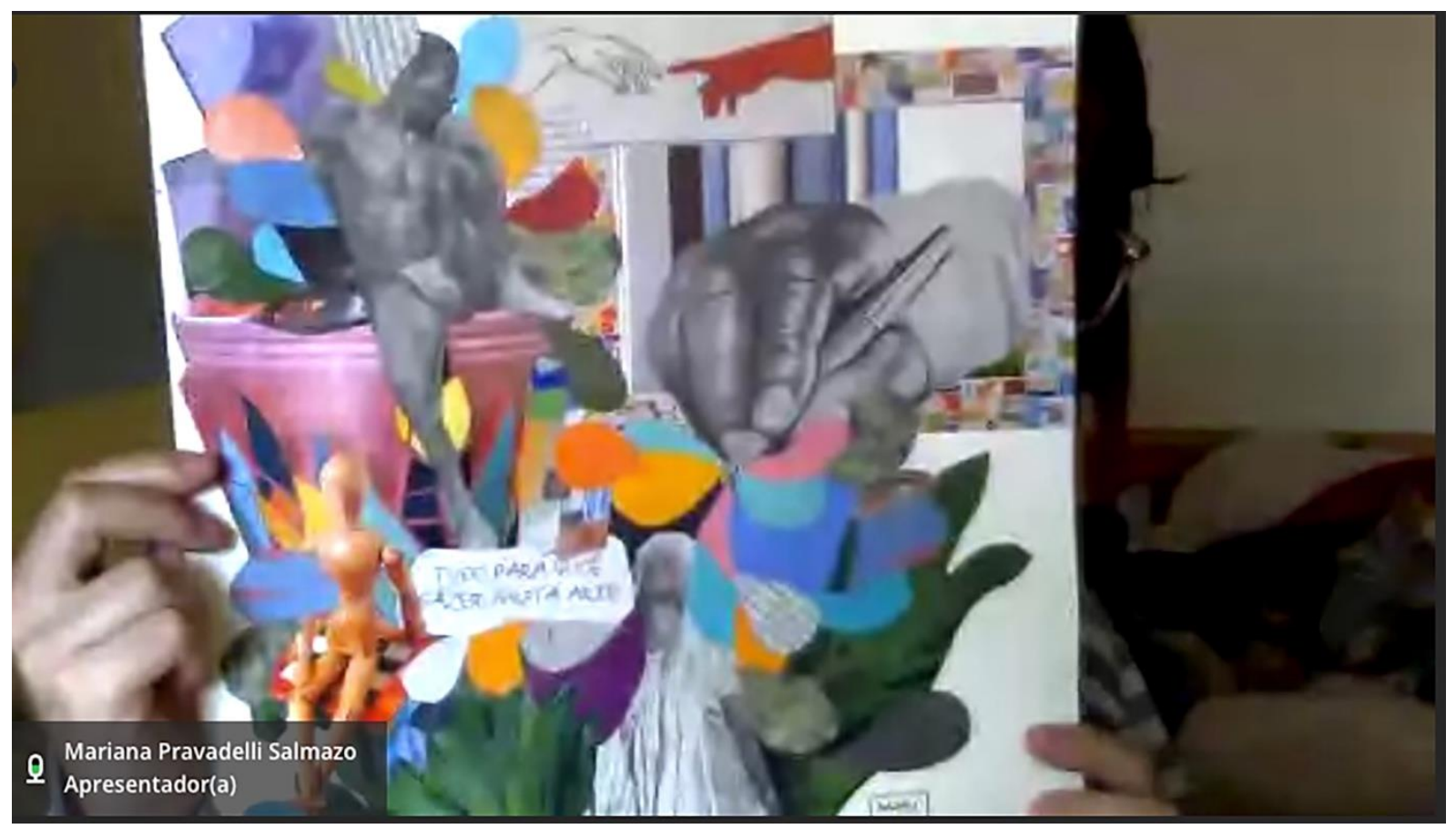

Fig. 2. Colagem realizada por Mariana Pravadelli Salmazo a partir do significado do verbo sentir, apresentado no ambiente virtual de aprendizagem, Blackboard, 2021. Screenshot realizado pelo autor.

Nesse sentido, compreendemos criação como rede complexa em construção, que estabelece interação, inter-relação e diálogo com o contexto cultural, com o tempo e o espaço da criação, bem como, envolvendo funções mentais de percepção, memória, raciocínio e emoção, ou seja, com processos cognitivos. A compreensão do processo de criação em rede móvel desenvolveu o raciocínio dos "mosaicos de fragmentos descontínuos", contra a ideia dos "modelos de influência”, por etapas lineares e sucessivas. "Todo o processo de design é tanto um processo criativo como um processo de solução de problema". ${ }^{12}$

Entendemos como rede em construção, numa perspectiva processual que descarta o mito de que, antes da criação, há apenas o vazio, o vácuo e a escuridão; ou, ainda, as explicações reducionistas e simplistas “[...] que poderosamente transformam o labirinto em uma trajetória linear, não apresentando nem sequer os desvios e bifurcações, distorcendo, assim, a complexidade lógica que envolve o ato criador" ${ }^{13}$

A possibilidade do uso do conceito de rede aplicado ao processo de criação se deve ao fato da noção de rede ser "[...] onipresente, e mesmo onipotente, em todas as disciplinas [...]" ${ }^{14}$ Tratando, portanto, de um grau de abstração que deve ser considerado, pois a análise parte do ponto de vista externo à rede, ou seja, do pesquisador. O percurso da criação, nesse caso, é multidimensional e se expande em direções para além das fronteiras da sala de aula. Quanto mais complexo o sistema, mais exige consciência do recorte proposto.

${ }^{12}$ LÖBACH, Bernd. Design industrial: bases para a configuração dos produtos industriais. $1^{\text {a }}$ ed., São Paulo: Edgard Blücher, 2001, p, 141.

${ }^{13}$ SALLES. Op. cit., p.22.

${ }^{14}$ Musso, Pierre. A filosofia da rede. In: PARENTE, André (Org.). Tramas da rede: novas dimensões filosóficas, estéticas e políticas da comunicação. Porto Alegre: Sulina, 2010, p. 17-18. 


\section{Linguagens múltiplas em construção}

A atomização dos meios e suportes analógicos e digitais para o desenvolvimento e circulação dos documentos de processo no fluxo da criação, indica sua expansão numa rede dinâmica e móvel que combina e entrelaça materialidades de naturezas diversas. Desse modo, professores e alunos desenvolvem conteúdos teóricos e atividades práticas entrelaçando suportes e plataformas variadas, são sketchbooks, blocos de anotações, cadernos de colagens, painéis, memoriais, relatórios, mockups, modelos físicos e protótipos tridimensionais, combinados com os objetos virtuais de aprendizagem, tais como: de comunicação e criação de comunidade (WhatsApp, Telegram, Teams, Google Meet etc.), de avaliação e aprendizagem (Quizlet, Mentimeter, Poll Everywhere etc.), de organização de ideias (Miro, Trello, Padlet, Mural etc.), de produção de conteúdo (Podcast, Pinterest, Instagram etc.) e de modelagem e prototipagem (impressão 3D, corte a laser, máquinas de comando numérico computadorizado etc.). Assim, os documentos de criação cruzam fronteiras e estabelecem o trânsito e fluxo contínuo entre analógico e digital, possibilitando modos e meios de interação e comunicação que agilizam as interlocuções, armazenam dados em volume expressivo e compartilham informações em rede.

Sabemos que no âmbito do ensino remoto do design o uso imbricado desses documentos através do processo de criação, geram as manobras e articulações dos modos de pensamento dados nas conexões e interações do método de projeto em design com as ações do aluno, em suas estratégias processuais criativas em rede. No entanto, as interações entre professores e alunos, bem como, a intensidade, frequência, sequência e ordem desses instrumentos, recursos e suportes de visualização são variáveis, que se manifestam sob mais de uma forma ou aspecto. Seja em termos de ambientes físicos ou espaços digitais, sabemos que o desafio se encontra no fluxo contínuo instável entre as salas de aula, laboratórios, oficinas, ambientes virtuais de aprendizagem e outros, pois assim também se dá na práxis do design.

Naturalmente, o domínio e uso das linguagens visuais bidimensionais e tridimensionais potencializam as interlocuções durante as orientações e discussões sobre o projeto. O modo como se dá o desenvolvimento e direcionamento do diálogo entre professores e alunos, está relacionado a utilização dos documentos de processo, ou seja, o rendimento do aluno no projeto é proporcionam ao uso destes recursos de comunicação na criação e projeto, pois as ideias se cruzam numa frequência e ritmo que possibilita descobertas para os interlocutores. As conversas ativadas a partir dos documentos propiciam ao aluno compreender que a criação se dá na interação que afeta o outro, produzindo tensão e confronto, fazendo o aluno reagir e mover o seu pensamento para estabelecer conexões significativas e construir ideias novas.

\section{Documentos de processo em trânsito}

Entendemos que as estruturas internas do pensamento do criador não estão visíveis, o conteúdo do processo de criação, ou seja, o pensamento em ação não é acessível, exigindo o uso de procedimentos e recursos materiais para ser revelado seus fragmentos. Nesse sentido, a compreensão das manobras e articulações do pensamento na criação requer corpus, ou seja, um conjunto de materialidades na forma de documentos sobre o que se busca. Portanto, as atividades de projeto em design no contexto de ensino, mostram que o desenvolvimento e uso dos documentos de processo de criação, tornou-se essencial e imprescindível no processo de interação e interlocução entre professores e alunos no ensino remoto.

Os designers se comunicam essencialmente e por meio da linguagem visual, seja bidimensional ou tridimensional, representando ideias e conceitos na forma de imagens visuais e modelos físicos. Como foi exposto, "os documentos de processo são, portanto, registros materiais do processo criador. São retratos temporais de uma construção que agem como índices do percurso criador". ${ }^{15}$

\footnotetext{
${ }^{15}$ SALLES. Op. cit., p. 26.
} 
Para o crítico de processo, sobretudo, os documentos são marcas, sinais, índices e rastros de materialidades de naturezas diversas, que compõem redes de significados, abrindo as tramas do pensamento criador, e expondo os artifícios, procedimentos, táticas e estratégias existentes no processo de criação. No entanto, por mais amplo e completo que tais documentos sejam, sabemos que eles não representam a criação em si. O caráter de experimentação dos documentos revela como o pensamento do aluno se desenvolve nas suas estratégias processuais criativas em rede, dadas nos diálogos intrapessoais e interpessoais, "[...], deixando transparecer a natureza indutiva da criação. Nesse momento de concretização da obra, hipóteses de naturezas diversas são levantadas e vão sendo testadas”. ${ }^{16}$

O caráter comunicacional dos documentos permite que autor desenvolva compreensão sobre o próprio processo, bem como, que outros decifrem as mensagens contidas nas marcas e sinais produzidos na criação. Assim, identificamos quatro circunstâncias gerais. São documentos que apresentam os aspectos detonadores da criação: como dispositivos, elementos e fatos que provocam a ativação e liberação de ideias; aspectos direcionadores: que indicam preferências, tendências e gostos, orientando as escolhas e decisões estratégicas; procedimentos organizadores. que indicam os modos de associação, classificação e composição dos dados, informações e elementos de configuração; bem como, a ação comunicacional: dada na relação, interação e interlocução, interpessoal e intrapessoal no processo de criação. São aspectos gerais que representam os processos complexos do movimento criador. Consequentemente, um conjunto de recursos no processo que "[...] pode aumentar significativamente a produtividade de uma equipe ao sustentar melhor colaboração entre seus membros e melhor comunicação com parceiros externos [...]". ${ }^{17}$

Incluímos na leitura e análise dos documentos de processo informações sobre escolhas, preferências, gostos, crenças, valores e visão do mundo, ou seja, sobre seu modo de pensar, de articular ideias, a respeito de conceitos e conhecimentos adquiridos nas disciplinas e na experiência do aluno criador. Assim, além dos eventos isolados os documentos trazem vestígios, marcas, sinais e índices dos aspectos socioculturais da criação. Consequentemente, contam sobre o propósito para o qual foram feitos, assim como sobre as mudanças e transformações ocorridas na criação, às vezes, adquirindo significados para além da intenção original de quem os utilizou e produziu. "Os documentos de processo são, portanto, registros materiais do processo criador. São retratos temporais de uma construção que agem como índices do percurso criativo" ${ }^{18}$

Dentre os múltiplos documentos utilizados no processo de desenvolvimento do Projeto Sentir, tais como, rascunhos, esboços, ilustrações, desenhos, fotografias, anotações, colagens, painéis, esquemas e diagramas com imagens e textos, arquivos em vídeos e áudios, modelos tridimensionais e outros, tanto no formato analógico quanto no digital, destacamos o dossiê memorial do projeto em design, documento comumente utilizado nos cursos de design que relata, descreve e detalha as fases e atividades desenvolvidas durante as aulas, apresentado como exigência parcial para concluir as disciplinas de projeto. Esse documento revela o percurso e jornada do aluno no processo de aprendizagem, ou seja, a rede da criação construída a partir dos múltiplos diálogos.

"Essa arqueologia da criação tira esses materiais da gaveta e dos arquivos e coloca-os em movimento reativando a vida neles guardada". ${ }^{19}$ O exercício de leitura, entendimento e compreensão da relação e do fluxo entre os documentos de processo na formação do designer é significativo para expandir a consciência do processo de criação. Assim, o desafio de estudar os documentos no âmbito do ensino remoto é, ao mesmo tempo, aprender a estabelecer vínculo, lógica e nexo dos fragmentos da criação com o todo.

\footnotetext{
${ }^{16}$ Ibidem., p. 27. Elsevier, 2010, p. 34.

${ }^{18}$ SALLES. Op. cit., p. 26.

${ }^{19}$ Ibidem., p. 23.
}

${ }^{17}$ BROWN, Tim. Design Thinking: uma metodologia poderosa para decretar o fim das velhas ideias. Rio de Janeiro: 
Os documentos de processo no ensino do design apresentam ferramentas potenciais para o desenvolvimento do pensamento do aluno pois evidenciam, materializam e tornam visual aspectos e conteúdos que estariam obscurecidos e disfarçados na linguagem verbal. Diante dos desafios, questões, problemas, restrições e possibilidades que compõem o contexto do projeto, o aluno é levado a refletir, avaliar, decidir e escolher. Portanto, detonam diálogos internos, em que o aluno estabelece conjecturas e inferências com base em presunções, evidências incompletas ou pressentimentos.

Esses documentos são suportes de auxílio cognitivo na inter-relação estabelecida, permitindo que o aluno consiga enxergar o todo e o específico. São artifícios próprios para ativar reflexões e discussões, que permitem conhecer o exercício projetual, a partir de alterações, ajustes ou correções do trajeto inicial, ativando uma construção do desenvolvimento, e a respeito do próprio modo de pensar sobre criação em design.

\section{Consciência da criação no trânsito entre os documentos de processo}

Dar ênfase aos processo de design não significa fazer apologia em defesa dos documentos originais, das marcas e sinais produzidos no percurso da criação, mas, prioritariamente, promover no ensino remoto do design reflexões sobre os procedimentos e práticas do processo de criação, no sentido de expandir a consciência do aluno em relação as estratégias criativas em rede, numa abordagem de metacriação, no sentido de compreender a dinâmica da criação para além da configuração e da linguagem visual-formal, revelando entendimento sobre os estratos das escolhas e decisões, individuais e/ou coletivas no percurso da criação. Nesse sentido, metacriação encontra-se adjacente ao conceito de metadesign ${ }^{20}$, que estuda o movimento dos elementos de um sistema, procurando estabelecer as regras segundo as quais os elementos podem se mover. "Pensar em design não como um corpo doutrinador fixo e imutável, mas como um campo em plena evolução. Algo que cresce de modo contínuo e se transforma ao crescer". ${ }^{21}$

Sem a possibilidade de reflexão sobre tais manobras e articulações, reforçamos as normalizações culturais, que evidenciam a solução final do projeto. As tensões, embates e antagonismos entre lógica e intuição, por sua vez, tidas como da natureza do design, estão, muitas vezes, subjacentes e encobertas pelos modelos e paradigmas estabelecidos de representação visual.

Teoria e senso comum, conceitos e pré-conceitos, conhecimentos e intuição são pares constantes no decorrer de projetos, em magnitude tal que muitas vezes os fundamentos teóricos constantes nos projetos são introduzidos, a posteriori, para justificar resultados previamente alcançados através de recursos extracientíficos. ${ }^{22}$

Essas reflexões são componentes integrantes do exercício do pensamento complexo e da natureza transdisciplinar do design. "A grande resistência à criação se deve ao fato de que ela é perigosa e subversiva, pois coloca em questão paradigmas estabelecidos. O próprio sistema de ensino, por exemplo, seja ele acadêmico ou não, obedece a cânones que devem ser seguidos [...]” ${ }^{23}$

Ao analisar os documentos de processo, de modo a restituir e pôr de volta os pensamentos, ideias e ações, procuramos "patrimonializar", de certa maneira, o conhecimento a partir da "narrativa da criação". A proposição permite ao aluno compreender a rede que estrutura e move as escolhas e decisões, bem como averiguar as relações da solução final de produto em conexão com os princípios direcionadores, tendências e com as circunstâncias e condições de espaço e tempo. O que

\footnotetext{
${ }^{20}$ VAN ONCK, Andries. Metadesign. Produto e Linguagem. Ano 1. Trad. Lucio Grinover. Associação Brasileira de Desenho Industrial: São Paulo, 1965, p. 29.

${ }^{21}$ CARdoso, Rafael. Design para um mundo complexo. São Paulo: Cosac Naify, 2012, p. 238.

${ }^{22}$ BOMFIM e PORTINARI. Op. cit., p. 42.

${ }^{23}$ Ibidem., p. 54.
} 
possibilita, igualmente, perceber como informações, conceitos, teorias e conhecimentos, bem como, diálogos com os interlocutores, podem provocar abandonos, recuos, substituições e saltos, ao longo do percurso.

[...] determinado PROJETO envolve uma elaboração complexa de ações previamente conhecidas e rotuladas, combinadas a outras nem sempre conscientes, que vão ganhando forma durante o processo de trabalho. E que, sobretudo, se deve recuperar o processo através do registro de maneira particularizada de se trabalhar cada etapa percorrida. A busca da consciência dos métodos compreendidos no processo é a grande riqueza que se passa para a posteridade. ${ }^{24}$

\section{Cruzamento entre espaços fisicos e ambientes digitais}

As atividades desenvolvidas no ensino buscam por simular sob certas condições a prática do projeto em design. As instituições de ensino que oferecem certa autonomia, flexibilidade e trânsito no uso dos espaços físicos e ambientes virtuais, eliminando fronteiras e provocando o fluxo entre analógico e digital como componente do programa de ensino, abrem espaço para o desenvolvimento de possibilidades criativas no ato de projetar.

Como foi exposto inicialmente, no contexto do ensino remoto experienciado a partir de 2020, a residência dos professores e alunos se transformaram em sala de aula, laboratórios e oficinas, naturalmente com as limitações, restrições e possibilidades que cada espaço indivíduo oferece. Assim, materiais e ferramentas disponíveis em casa serviram de instrumentos para executar mockups, modelos físicos e protótipos tridimensionais, seguindo a lógica do "faça você mesmo". Consequentemente, ativando e impulsionando a capacidade do professor e alunos desenvolverem conexões criativas diante das barreiras impostas.

No entanto, sabemos que a experiência de aprendizagem exclusivamente remota e circunstancial não exclui ou substitui a integração e trânsito entre sala de aula, laboratórios e oficinas como fator determinante para a dinâmica do ensino do projeto em design, pois a interação física e a relação temporal impulsionam experimentos e descobertas num fluxo contínuo, sem interrupções ou fronteiras. Assim, os diálogos e discussões entre os alunos e destes com os professores e técnicos dos laboratórios e oficinas, configuram ambientes expandidos de experimentação e descoberta, ativado por meio das trocas e diálogos, potencializando e viabilizando a geração de ideias, conceitos e soluções concretas e factíveis. Logo, o contexto de formação que dispõe do trânsito analógico e digital na sua estrutura e programa de ensino, permite a flexibilidade que será demandada na aprendizagem amanhã.

Nesse sentido, o aluno precisa mexer, experimentar, errar, corrigir e acertar. Essa abertura sob condições de controle e segurança deve ser considerada, pois é precisa passar pela via da investigação e descoberta. Caso contrário, será negada a possibilitar de aprender interagindo com os efeitos da materialidade, que caracterizam e definem de certo modo a efetividade do projeto em design.

\section{Conclusão}

Discutir uma proposta conceitual e preliminar para repensar o ensino do projeto de design sob a perspectiva das conexões e interações que se estabelecem no processo de design, oferece alguns índices que geram reflexões críticas sobre os modos de desenvolvimento do pensamento do aluno, através das estratégias processuais criativas, próprias das articulações do pensamento entre o conhecimento tácito, que está subjacente nas experiências, as representações produzidas na criação, e o conhecimento explícito que está posto, modelado e programado pelos preceitos do design, oferecendo a possibilidade de ampliar esse estudo em projetos seguintes numa aproximação com o ensino e a práxis do design. Assim, as conclusões efetivas

${ }^{24}$ CoelHo. Op. cit., p. 251. 
sobre o desenvolvimento desse estudo serão obtidas a partir das interações articuladas e produzidas no contexto das novas modalidades de ensino.

Diante do momento de oscilação e transformação marcado pelo paradoxo da inquietude e diante dos desafios do ensino e aprendizagem, buscamos pelo movimento de aproximação e recuo dos preceitos do campo do design, a fim de possibilitar uma leitura que permitisse discutir estratégias para os novos contextos do ensino do projeto de design como espaço de reflexão. O fluxo, trânsito e cruzamento entre documentos de processo de criação, analógicos e digitais, quando utilizados de modo consciente, geram conhecimento sobre o próprio processo, no exercício da metacriação. No percurso das atividades de projeto, os documentos de processo de criação apontam para aspectos detonadores, direcionadores, organizadores e comunicacionais do processo de criação no âmbito do projeto de design. Assim o aluno deve ser capaz de observar, analisar e interpretar criticamente seu processo de design, como modo de desenvolvimento do pensamento do design, bem como, da consciência das próprias estratégias processuais criativas em rede.

As experiências desenvolvidas na disciplina Projeto Sentir revelam que os desafios e oportunidades a partir do ensino remoto apontam para pesquisas relacionadas ao entrelaçamento, curso, fluxo e trânsito entre os documentos de processo de criação no ensino do design, como possibilidade de discutir aspectos relacionados aos suportes, ferramentas, objetos, linguagens e procedimentos criativos. Nessa condição e contexto do ensino remoto compreendemos como interagir com as ações dos alunos em suas estratégias processuais criativas em rede, bem como, acessar e compreender as manobras e articulações do pensamento do aluno no processo de design. Afinal, é na construção dos documentos de processo de criação que o aluno enfrenta desafios, amplia suas habilidades e desenvolve a consciência do ato de projetar, ou seja, compreende a complexa rede da criação.

\section{Referências}

BERNSEN, Jeans. Design: defina primeiro o problema. SENAI/LBDI, 1995.

Bomfim, Gustavo A. e Portinari, Denise B. Epistemologia do design. In: Couto, Rita Maria de S., FArbiarz, Jackeline L e NovAEs, Luiza (Ogs.). Gustavo Amarante Bomfim uma coletânea. Rio de Janeiro: Rio Book’s, 2014.

BomfIM, Gustavo A. Metodologia para desenvolvimento de projetos. João Pessoa: Editora Universitária, 1995.

BRown, Tim. Design Thinking: uma metodologia poderosa para decretar o fim das velhas ideias. Rio de Janeiro: Elsevier, 2010.

BÜRDEK, Bernhard E. História, teoria e prática do design de produtos. São Paulo: Edgard Blücher, 2006.

CARDOSO, Rafael. Design para um mundo complexo. São Paulo: Cosac Naify, 2012.

CARDOSO, Rafael. Uma introdução à história do design. São Paulo: Editora Edgard Blucher, 2000.

Coelho, Luiz Antônio L. (Org.). Conceitos-chave em design. Rio de Janeiro: Ed. PUC-Rio. Novas Ideias, 2011.

LÖBACH, Bernd. Design industrial: bases para a configuração dos produtos industriais. $1^{\mathrm{a}}$ ed., São Paulo: Edgard Blücher, 2001.

Musso, Pierre. A filosofia da rede. In: PARENTE, André (Org.). Tramas da rede: novas dimensões filosóficas, estéticas e políticas da comunicação. Porto Alegre: Sulina, 2010. P. 17-38.

SALLES, Cecilia Almeida. Gesto Inacabado: processo de criação artística. 5ª ed., São Paulo: Intermeios, 2011. 
revista de crítica genética

SANTAELlA, Lúcia. Matrizes da linguagem e pensamento: sonoro, visual e verbal: aplicação na hipermídia. $3^{\mathrm{a}}$ ed., São Paulo: Iluminuras: FAPESP, 2005.

Recebido em: 30/06/2021 Aceito em: 08/10/2021 